\title{
Avaliação do glyphosate e paraquat no manejo da Brachiaria ruziziensis ${ }^{1}$
}

\section{Evaluation of glyphosate and paraquat in management of Brachiaria ruziziensis}

\author{
Neumárcio Vilanova Costa ${ }^{2}$; Eduardo Jorge de Lima Peres ${ }^{3}$; Lucas Ritter ${ }^{3}$; Pabluo Volpato \\ Silva $^{3}$; Emerson Fey ${ }^{2}$
}

Resumo - O objetivo deste trabalho foi o de avaliar o efeito de doses do paraquat e do glyphosate na dessecação da forrageira Brachiaria ruziziensis, na capacidade de rebrota e na formação de biomassa para o sistema de Integração Agricultura-pecuária. $\mathrm{O}$ delineamento experimental foi de blocos casualizados com quatro repetições. As doses do glyphosate foram 0 , $90,180,360,720$ e $1440 \mathrm{~g} \mathrm{ha}^{-1}$ e do paraquat foram $0,50,100,200,400$ e $800 \mathrm{~g} \mathrm{ha}^{-1}$. Com base nos resultados obtidos pode-se concluir que o paraquat foi ineficiente na dessecação da $B$. ruziziensis e que o glyphosate foi eficiente apenas nas doses de 720 e $1440 \mathrm{~g} \mathrm{ha}^{-1}$. Não houve emissão de novos perfilhos após a dessecação com glyphosate das plantas da forrageira que permitisse utilização prática para manejo no sistema Integração Agricultura-pecuária.

Palavras-chaves: herbicida, plantio direto, sistemas de integração

\begin{abstract}
The objective of this study was to evaluate the effect of doses of paraquat and glyphosate on desiccation Brachiaria ruziziensis, the ability of regrowth and formation of biomass for the integration of crop-livestock system. The experimental design was randomized blocks with four replications. The rates glyphosate were $0,90,180,360,720$ and $1440 \mathrm{~g} \mathrm{ha}^{-1}$ and paraquat were $0,50,100,200,400$ and $800 \mathrm{~g} \mathrm{ha}^{-1}$. Based on the results obtained it can be concluded that paraquat was ineffective in desiccation B. ruziziensis and the glyphosate was only effective at rates of 720 and $1440 \mathrm{~g} \mathrm{ha}^{-1}$. There was no issuance of new tillers after desiccation with glyphosate plant forage to allow practical use for management in integration of croplivestock system.
\end{abstract}

Keywords: herbicide, tillage, systems integration

\footnotetext{
${ }^{1}$ Recebido para publicação em 13/08/2012 e aceito em 07/02/2013.

2 Docentes do Centro de Ciências Agrárias da Universidade Estadual do Oeste do Paraná (Unioeste), Marechal Cândido Rondon, PR, Brasil. Email: <neumarcio.costa@unioeste.br>. (Autor para correspondência).

${ }^{3}$ Discentes do curso de Agronomia Universidade Estadual do Oeste do Paraná (Unioeste).
} 


\section{Introdução}

O sistema de plantio direto tem-se mostrado muito mais que um método de conservação do solo e pode contribuir para a sustentabilidade da agricultura, mantendo altas produções (Amaral, 2001).

Uma proposta que pode colaborar com o sistema de plantio refere-se ao sistema de Integração Agricultura-pecuária. Neste sistema, ocorre o cultivo consorciado de forrageiras tropicais, em especial as espécies do gênero Brachiaria, com culturas anuais onde se destacam o arroz, feijão, milho, soja e sorgo (Portes et al., 2000; Jakelaitis et al., 2004; Freitas et al., 2005; Severino et al., 2006; Balbinot Junior et al., 2009). A espécie forrageira é manejada como planta anual, sendo utilizada para produção de forragem após a colheita da cultura produtora de grãos e, em seguida, para formação de palha para semeadura da próxima safra de verão no sistema plantio direto, ou até mesmo como pasto para o gado ou outros animais.

De acordo com Jakelaitis et al. (2005), para o sucesso da aplicação deste sistema de produção, devem-se levar em consideração as especificidades do local de cultivo, como o solo e o clima. Assim como, da utilização de forrageiras eficientes para produção de massa seca e com alta relação $\mathrm{C} / \mathrm{N}$ garantindo maior permanência da cobertura vegetal sobre o solo (Silva et al, 2006; Nunes et al., 2009).

Dentre as espécies com potencial de utilização no sistema de Integração Agricultura-pecuária destaca-se a Brachiaria ruziziensis. Esta espécie é nativa na parte oriental da República do Zaire, em Ruanda e Kenya, sendo introduzida como forrageira em diversas partes do mundo, inclusive no Brasil (Kissmann \& Groth, 1997). Alvim et al. (1990), constataram produção de massa seca de B. ruziziensis sem adubação superior a $6 \mathrm{t} \mathrm{ha}^{-1}$ ano $^{-1}$ e quando foi adubada com 75 e $150 \mathrm{~kg}$ $\mathrm{ha}^{-1}$ de nitrogênio, a gramínea obteve produções de massa seca próximas de 8,5 e $11,0 \mathrm{t} \mathrm{ha}^{-1}$ ano $^{-1}$, respectivamente.
No sistema de plantio direto, o manejo das forrageiras antes da semeadura é normalmente realizado com herbicidas de contato e sistêmicos, a exemplo do paraquat e do glyphosate, respectivamente. Estes herbicidas são aplicados em pós-emergência e classificados como não-seletivos. Apresentam amplo espectro de ação, o que possibilita excelente controle de plantas daninhas anuais ou perenes, tanto de folhas largas como estreitas (Rodrigues \& Almeida, 2005).

Segundo Almeida (1991), o manejo eficiente das plantas utilizadas como cobertura do solo é um dos fatores mais importantes para o sucesso do estabelecimento de culturas graníferas, pois permite que a cultura se desenvolva inicialmente livre de interferências. Entretanto, a ocorrência de falhas na dessecação pode levar a menor eficiência e rendimento da semeadora, principalmente pela dificuldade de corte da palhada o que pode causar desuniformidade no estande da cultura.

Outro aspecto que eleva os custos em áreas com Integração Agricultura-pecuária refere-se à dessecação da forrageira antes semeadura da cultura de interesse, o que exige a realização novamente da semeadura da espécie forrageira para formação de pasto e de palha para a safra seguinte. Ressalta-se que atualmente são escassos na literatura, trabalhos científicos que abordem este assunto, principalmente, quanto a informações referentes ao manejo químico de B. ruziziensis.

Portanto, a hipótese do presente trabalho baseia-se no fato que a utilização de espécies perenes como a $B$. ruziziensis pode eliminar a necessidade de aquisição freqüente de sementes de forrageiras e reduzir os custos de produção, uma vez que, gramíneas podem ser manejadas com sub-doses de paraquat e de glyphosate no momento da dessecação de modo a permitir a emissão de novos perfilhos a partir do término do período crítico de prevenção da interferência (PCPI), sem prejudicar o desenvolvimento da cultura em 
sucessão e proporcionar boa produção de fitomassa após a colheita.

O objetivo do presente trabalho foi o de avaliar o efeito de doses dos herbicidas glyphosate e paraquat na dessecação da forrageira Brachiaria ruziziensis, na capacidade de rebrota e na formação de biomassa para o sistema de Integração Agricultura-pecuária.

\section{Material e Métodos}

O experimento foi realizado no ano agrícola de 2011/12, na Fazenda Experimental Linha Guará, pertencente à Universidade Estadual do Oeste do Paraná (UNIOESTE), campus de Marechal Cândido Rondon, apresentando as seguintes coordenadas: $24^{\circ} 42^{\prime} 30^{\prime} ' S$ de latitude, 54 $21^{\prime} 10^{\prime}$ ' $\mathrm{W}$ de longitude e $485 \mathrm{~m}$ de altitude.

O solo da área experimental, cultivado há seis anos no sistema plantio direto, foi classificado como Latossolo Vermelho eutroférrico (LVedf), de textura muito argilosa e possui boa drenagem (EMBRAPA, 1999). As características químicas do solo foram: $\mathrm{pH}$ $\left(\mathrm{CaCl}_{2}\right)=4,94$; matéria orgânica $\left(\mathrm{g} \mathrm{dm}^{-3}\right)=$ 23,24; $\mathrm{P}\left(\mathrm{mg} \mathrm{dm}^{-3}\right)=17,43 ; \mathrm{H}+\mathrm{Al}, \mathrm{K}, \mathrm{Ca}, \mathrm{Mg}$, SB e CTC $\left(\right.$ cmolc $\left.\mathrm{dm}^{-3}\right)=3,14 ; 0,72 ; 5,24$; 2,$14 ; 8,10$ e 11,24; respectivamente; e $\mathrm{V} \%=$ 72,06 .

O delineamento experimental foi o de blocos casualizados, com quatro repetições. As doses do glyphosate foram $0,90,180,360,720$ e $1440 \mathrm{~g} \mathrm{ha}^{-1} \mathrm{e}$ do paraquat foram $0,50,100$, 200, 400 e $800 \mathrm{~g}$ ha $^{-1}$. Cada unidade experimental foi constituída de seis linhas da forrageira de $5 \mathrm{~m}$ de comprimento, espaçadas a 0,7 m em uma área total de 21,0 $\mathrm{m}^{2}$.

A dessecação da área foi realizada em 13/10/2011 utilizando-se o herbicida glyphosate (Atanor - $360 \mathrm{~g} \mathrm{~L}^{-1}$ ) na dose de 828 $\mathrm{g} \mathrm{ha}{ }^{-1}$.

Aos sete dias após a dessecação da área (20/10/2011) foi realizada a semeadura mecanizada da Brachiaria ruziziensis, utilizando-se uma semeadoura adaptada para o plantio de sementes de pastagem (COPAGRIL). As sementes foram misturadas ao adubo Super Fosfato Simples com $18 \%$ de $\mathrm{P}_{2} \mathrm{O}_{5}\left(155 \mathrm{~kg} \mathrm{ha}^{-1}\right.$ de SFS) para a distribuição de $10,0 \mathrm{~kg} \mathrm{ha}^{-1}$ de sementes da forrageira.

Após a semeadura, para evitar a matointerferência no desenvolvimento da forrageira, foram realizadas na área quatro operações de capinas manuais, quinzenalmente, até o fechamento das entre linhas.

A aplicação dos tratamentos foi realizada quando a braquiária apresentou pleno desenvolvimento (no florescimento 01/03/2012) e cobrindo totalmente a superfície do solo das unidades experimentais. Foi utilizando pulverizador costal pressurizado com $\mathrm{CO}_{2}$, com pressão constante de $207 \mathrm{kPa}$, equipado com quatro pontas tipo leque (Teejet XR 110.02), espaçadas em $0,5 \mathrm{~m}$ e posicionadas a $0,5 \mathrm{~m}$ da superfície do alvo, aplicando-se o equivalente a $200 \mathrm{~L} \mathrm{ha}^{-1} \mathrm{de}$ calda. As condições climáticas no momento das aplicações foram: 26,8 a $29,5{ }^{\circ} \mathrm{C}, 70$ a $74 \%$ umidade relativa do ar e $2,9 \mathrm{~km} \mathrm{~h}^{-1}$.

Os efeitos da dessecação das plantas de braquiária foram avaliados visualmente aos 4, 7, 14, 21, 28, 35 e 42 dias após a aplicação (DAA), por escala de percentual de notas, na qual 0 (zero) corresponde a nenhuma injúria demonstrada pela planta e 100 (cem) à morte das plantas, segundo a Sociedade Brasileira da Ciência das Plantas Daninhas - SBCPD (1995). Os parâmetros utilizados para estabelecimento das notas foram: inibição do crescimento, quantidade e uniformidade das injúrias, capacidade de rebrota das plantas, quantidade de plantas mortas e acúmulo de biomassa.

Após a finalização das avaliações de porcentagem de dessecação (42 DAA), iniciouse a contagem do número de perfilhos emitidos em $1 \mathrm{~m}^{2}$ amostrando na área central das parcelas. As avaliações foram realizadas aos 15, 30, 45 e 60 dias após a dessecação (DAD). A área foi identificada com estacas para facilitar a localização em cada avaliação. 
Aos 60 DAD foi avaliada a massa seca das plantas, para determinar o acúmulo de biomassa. Para isso, coletou-se a parte aérea das forrageiras, utilizando-se uma moldura metálica de $0,25 \mathrm{~m}^{2}$ de área, em duas amostragens por unidade experimental. O material coletado foi seco em estufa de circulação forçada de ar a $60{ }^{\circ} \mathrm{C}$; em seguida, pesado, e os dados, transformados em $\mathrm{t} \mathrm{ha}^{-1}$.

Os resultados foram submetidos à análise de variância e as médias ajustadas a modelos de regressão, sendo as equações escolhidas com base nos modelos significativos, com lógica biológica e de elevado $\mathrm{R}^{2}$.

\section{Resultados e Discussão}

Observou-se na Figura 1A, que as doses de 90 e $180 \mathrm{~g} \mathrm{ha}^{-1}$ do glyphosate apresentaram dessecação inferior a $50 \%$ em todas as datas de avaliação, já na dose de $360 \mathrm{~g} \mathrm{ha}^{-1}$ observou um inicio de controle aos 7 DAA, tendo aos 42 DAA dessecação de $73,8 \%$, não sendo eficiente para o manejo da Brachiaria ruziziensis.

Aos 14 DAA as doses de 720 e $1440 \mathrm{~g}$ $\mathrm{ha}^{-1}$ apresentaram eficiência superior a $80 \%$, sendo que aos 28 DAA, estas doses porcionaram 93 e $98 \%$ de dessecação das plantas de $B$. ruziziensis, respectivamente. Pode-se observar ainda que a dose de $1440 \mathrm{~g}$ $\mathrm{ha}^{-1}$ apresentou controle de $98 \%$ aos 21 DAA, e se manteve estável nas demais datas de avaliação.

Segundo Brighenti et al. (2011), existe variabilidade entre as espécies de $B$. brizantha, B. decumbens e $B$. ruziziensis, quanto à suscetibilidade ao herbicida glyphosate, sendo que a $B$. ruziziensis foi a mais suscetível. Os autores citam ainda que o conhecimento da suscetibilidade diferencial entre as espécies de Brachiaria avaliadas permite uma economia de 12 a $16 \%$ na dose do herbicida glyphosate. Desta maneira, como as doses de 720 e 1440 g $\mathrm{ha}^{-1}$ de glyphosate foram eficientes na dessecação das plantas de $B$. ruziziensis, pode se utilizar a dose de $720 \mathrm{~g} \mathrm{ha}^{-1}$ visando diminuição dos custos de manejo ou $1440 \mathrm{~g} \mathrm{ha}^{-}$ ${ }^{1}$ quando o objetivo for rapidez no manejo de dessecação.

Timossi et al. (2006) avaliando a porcentagem de controle de $B$. decumbens e $B$. brizantha, observaram 99,5 e $98,5 \%$ de controle, respectivamente, aos 28 DAA com aplicação de $2880 \mathrm{~g} \mathrm{ha}^{-1}$ de glyphosate. Esta dose foi muito superior às utilizadas no presente trabalho.

Para o Paraquat (Figura 1B) a dose de $800 \mathrm{~g} \mathrm{ha}^{-1}$ apresentou eficiência de cerca de $80 \%$ até aos 14 DAA, contudo, após este período não se observou controle eficiente em nenhuma das doses aplicadas, visto que as plantas estavam em pleno desenvolvimento vegetativo, impossibilitando que o herbicida atingisse todas as suas folhas, requeimando assim apenas as folhas superiores e apresentando controle satisfatório somente nas duas primeiras datas de avaliação.

Ressalta-se que com o passar do tempo as plantas de B. ruziziensis voltaram a emitir folhas novas, o que se explica a diminuição da eficiência da dessecação das plantas. Destacase ainda que as diferenças na eficiência na dessecação do glyphosate e do paraquat pode ser atribuída a ação sistêmica e de contato dos herbicidas, respectivamente.

Skóra Neto et al. (1995), citam que a mistura de paraquat + diuron $\left(200+100 \mathrm{~g} \mathrm{ha}^{-1}\right)$, promoveram controle inferiores a $60 \%$ da aveia-perta (Avena strigosa) em aplicações com volumes de calda entre 100 a $325 \mathrm{~L} \mathrm{ha}^{-1}$. Entretanto, Garcia et al. (2004), verificaram que a dessecação da aveia-preta com a mistura de paraquat + diuron na mesma dose, promoveu controle de 82,5 e $80,3 \%$ quando utilizou-se volumes de calda de 300 e 400 L ha $^{-}$ ${ }^{1}$, respectivamente. Estes volumes de calda são superiores ao utilizado no presente trabalho (200 $\mathrm{L} \mathrm{ha}^{-1}$ ), o que pode ter favorecido a melhor deposição da calda nas plantas e potencializado o efeito do paraquat que é um herbicida de contato. 
Maciel et al. (2011), citam que a aplicação do paraquat com a adição do adjuvante Silwet ${ }^{\circledR}\left(300 \mathrm{~g} \mathrm{ha}^{-1}+0,1 \% \mathrm{v} \mathrm{v}^{-1}\right)$, utilizando-se o volume de calda de $200 \mathrm{~L} \mathrm{ha}^{-1}$, promoveu controle de 99 e $98 \%$, no manejo de dessecação da $B$. decumbens e B. humidicola, respectivamente. Desta forma, para o manejo de dessecação da $B$. ruziziensis com o paraquat ser eficiente deve-se considerar o uso de volumes de caldas elevados e/ou de adjuvantes para maximizar a deposição das gotas.

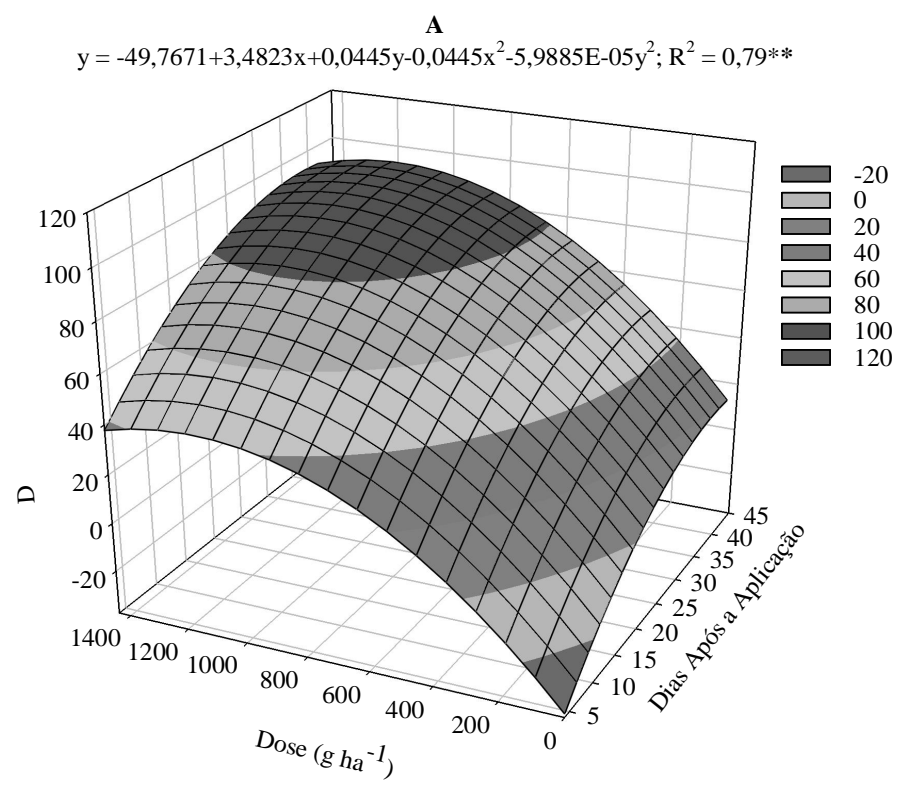

$y=23,9101-1,2241 x+0,1454 y+0,0049 x^{2}-9,5153 E-05 y^{2} ; R^{2}=0,85^{* *}$

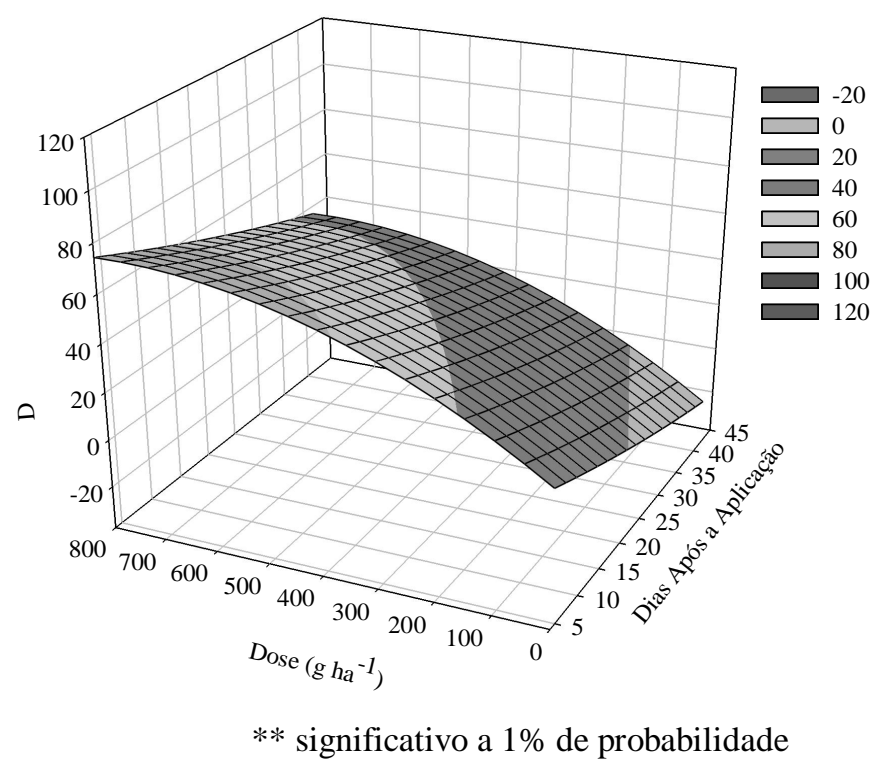

Figura 1. Porcentagem de dessecação da B. ruziziensis após a aplicação de diferentes doses de glyphosate (A) e paraquat (B) ao longo do período de avaliação. 
Houve decréscimo da produção da que em todas as doses de paraquat não se massa de matéria seca com o aumento da dose dos herbicidas (Figura 2). Destaca-se que não observou emissão de novos perfilhos após a obteve controle da $B$. ruziziensis, o que não permitiu avaliar a emergência de novos perfilhos. dessecação das plantas com glyphosate, sendo
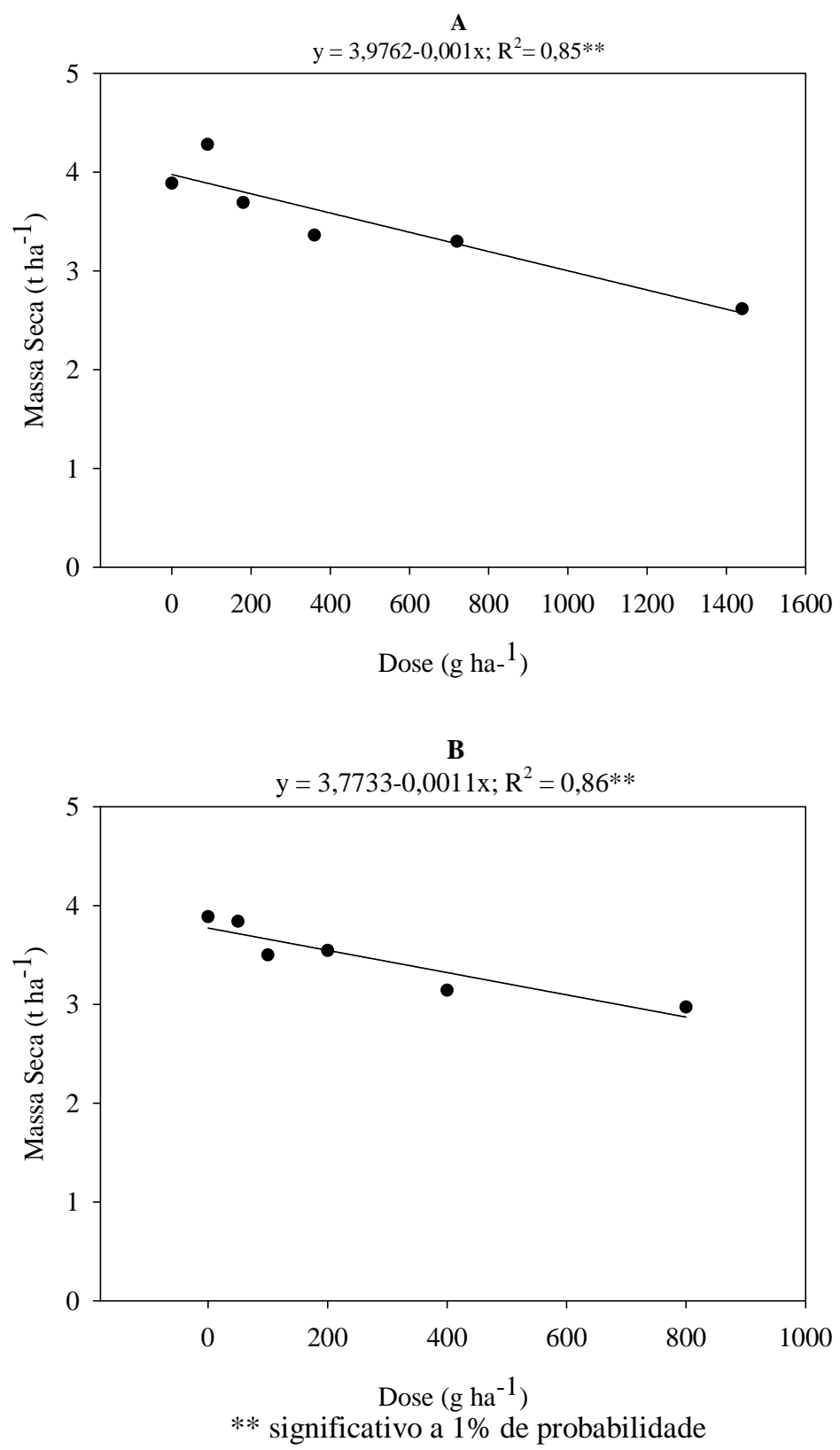

Figura 2. Massa da matéria seca da B. ruziziensis após a aplicação de diferentes doses de glyphosate (A) e paraquat (B) aos 60 dias após a dessecação.

Este fato, não corrobora com a hipótese glyphosate e paraquat no momento da do presente trabalho de que a $B$. ruziziensis dessecação de modo a permitir a emissão de pode ser manejada com os herbicidas novos perfilhos para utilização no sistema de 
Integração Agricultura-pecuária e proporcionar boa produção de fitomassa após a colheita cultura produtora de grãos.

Contudo, Ferri et al. (2001), ao avaliar o efeito de herbicidas dessecantes sobre pastagens nativas constituídas por diferentes espécies do gênero Paspalum, observaram que houve recuperação total da pastagem aos 290 dias após a aplicação de doses inferiores a 450 $\mathrm{g} \mathrm{L}^{-1}$ de glyphosate e para as doses de $600 \mathrm{e}$ $800 \mathrm{~g} \mathrm{~L}^{-1}$ de paraquat, o que permitiu inferir que estes herbicidas podem ser utilizados na supressão de pastagens nativas de Paspalum spp. quando se deseja realizar a sobressemeadura de espécies forrageiras como aveia-preta, sem causar prejuízo significativo quanto ao estabelecimento da pastagem nativa no futuro.

Desta forma, mais estudos devem ser realizados para aprimorar a técnica de manejo da dessecação da B. ruziziensis.

\section{Conclusões}

Com base nos resultados obtidos podese concluir que o paraquat foi ineficiente na dessecação da $B$. ruziziensis e que o glyphosate foi eficiente apenas nas doses de 720 e $1440 \mathrm{~g}$ $\mathrm{ha}^{-1}$. Entretanto, não houve emissão de novos perfilhos após a dessecação com glyphosate das plantas da forrageira que permitisse utilização prática para manejo no sistema de Integração Agricultura-pecuária.

\section{Referências}

ALMEIDA, F.S. Controle de plantas daninhas em plantio direto. Londrina: IAPAR, 1991. 34 p. (Circular, 67)

ALVIM, M.J. et al. Aplicação de nitrogênio em acessos de Brachiaria. 1. Efeito sobre produção de matéria seca. Pasturas Tropicales, v.12, n.2, p.2-6, 1990.

AMARAL, M. Plantio direto evolui no Brasil. Informe Agropecuário, v.22, n.1, p.3-8, 2001.
BALBINOT JÚNIOR, A.A. et al. Integração lavoura-pecuária: intensificação de uso de áreas agrícolas. Ciência Rural, v.39, n.6, p.1925-1933, 2009.

BRIGHENTI, A.M. et al. Suscetibilidade diferencial de espécies de braquiária ao herbicida glifosato. Pesquisa Agropecuária Brasileira, v.46, n.10, p.1241-1246, 2011.

CONAB-Companhia Nacional de Abastecimento. Acompanhamento de safra brasileira: grãos, sétimo levantamento, abril 2010. Brasília, 2010. 42p.

EMBRAPA - EMPRESA BRASILEIRA DE PESQUISA AGROPECUÁRIA. Sistema brasileiro de classificação dos solos. Rio de Janeiro: 1999. 412p.

FERRI, M.V.W. et al. Aplicação de herbicidas dessecantes em pastagens nativas constituídas por diferentes espécies do gênero Paspalum. Ciência Rural, v.31, n.4, p.589-595, 2001

FREITAS, F.C.L. et al. Cultivo consorciado de milho para silagem com Brachiaria brizantha no sistema de plantio convencional. Planta Daninha, v.23, n.4, p.635-644, 2005.

GARCIA, L.C. et al. Dessecação da aveia-preta (Avena strigosa Schreb) com herbicida de contato, em presença ou não de assistência de ar junto à barra do pulverizador, em diferentes volumes de calda. Engenharia Agrícola, v.24, n.3, p.758-763, 2004.

JAKELAITIS, A. et al. Efeitos de herbicidas no consórcio de milho com Brachiaria brizantha. Planta Daninha, v.23, n.1, p.69-78, 2005.

JAKELAITIS, A. et al. Manejo de plantas daninhas no consórcio de milho com capimbraquiária (Brachiaria decumbens). Planta Daninha, v.22, n.4, p.553-560, 2004.

KISSMANN, K.G.; GROTH, D. Plantas infestantes e nocivas. 2.ed. São Paulo: BASF, 1997. Tomo I. 825p. 
MACIEL, C.D.G. et al. Eficiência de paraquat e MSMA isolados e associados a adjuvantes no manejo de plantas daninhas. Global Science and Technology, v.4, n.1, p.70-81, 2011.

NUNES, A.S. et al. Épocas de manejo químico de Brachiaria decumbens antecedendo o plantio direto de soja. Planta Daninha, v.27, n.2, p.297-302, 2009.

PORTES, T.A. et al. Análise do crescimento de uma cultivar de braquiária em cultivo solteiro e consorciado com cereais. Pesquisa Agropecuária Brasileira, v.35, n.7, p.13491358, 2000.

RODRIGUES, B.N.; ALMEIDA, F.S. Guia de herbicidas. 5 ed. Londrina, 2005, 592p.

SBCPD-SOCIEDADE BRASILEIRA DA CIÊNCIA DAS PLANTAS DANINHAS. Procedimentos para instalação, avaliação e análise de experimentos com herbicidas. Londrina: 1995. 42p.

SEVERINO, F.J.; CARVALHO, S.J.P.; CHRISTOFFOLETI, P.J. Interferências mútuas entre a cultura do milho, espécies forrageiras e plantas daninhas em um sistema de consórcio. II - implicações sobre as espécies forrageiras. Planta Daninha, v.24, n.1, p.4552, 2006.

SILVA, A.C. et al. Dessecação pré-colheita de soja e Brachiaria brizantha consorciadas com doses reduzidas de graminicida. Pesquisa Agropecuaria Brasileira, v.41, n.1, p.37-42, 2006.

SKÓRA NETO, F. et al. Eficácia de herbicidas na dessecação de aveia-preta para formação de cobertura morta em plantio direto. Planta Daninha, v.13, n.2, p.81-86, 1995.

TIMOSSI, P.C.; DURIGAN, J.C.; LEITE, G.J. Eficiência de glyphosate em plantas de cobertura. Planta Daninha, v.24, n.3, p.475480, 2006. 